\title{
Call for Papers, CPSA 1983 Annual Meeting
}

Members of the Association are invited to submit proposals for papers to be presented at the Annual Meeting of the Canadian Political Science Association to be held at the University of British Columbia, Vancouver, B.C., June 6, 7, and 8, 1983.

A proposal should include: a title; a summary (about 300 words) of the argument of the paper; and a description of the method of analysis.

Proposals may be submitted to any member of the Programme Committee listed below. The Committee invites suggestions concerning topics for panels and plenary sessions as well as proposals for papers. Those which do not fit into any specific section should be sent to the chairperson.

The deadline for submission of proposals is November 2, 1982.

Completed papers should be not more than 30 pages in length, double-spaced, and should not have been previously published.

Papergivers are required to provide the CPSA secretariat with two copies of their paper by May 1 and to prepare up to 100 copies for distribution to members.

Programme Committee Chairperson: R. K. Carty, Department of Political Science, University of British Columbia, Vancowver. B.C., V6T IW5

Vice-Chair: (1984 Chairperson) Michael Atkinson, Department of Political Science, McMaster University, Hamilton, Ontario L8S 4M4

Local Representative: John Wood, Department of Political Science, University of British Columbia, B.C., V6T IW5

Section

Canadian Politics

Provincial Politics

Political Sociology

Public Policy, Administration and Law

Political Theory/

Political Analysis

\section{Section head}

TBA

Michael Atkinson, Department of Political Science, McMaster University, Hamilton, Ontario L8S 4M4

Michael Atkinson, (please note address above)

T. Morley, Department of Political Science, University of Victoria, Victoria, B.C., V8W 2 Y2

D. Carmichael, Department of Political Science, University of Alberta, Edmonton, Alberta T6G 2E1

Papers under the rubric "Political Analysis and History" should be submitted to this section. If enough high-quality submissions are received, two separate series of sessions may be organized.

Comparative Politics: TBA

Western Capitalist

Comparative Politics

(State) Socialist

Political Economy

International Relations

Lenard Cohen, Department of Political Science, Simon Fraser University, Burnaby, B.C. V5A 1S6

Garth Stevenson, Department of Political Science, University of Alberta, Edmonton, Alberta T6G 2E1

E. Smythe, International Division, Department of Federal and Inter-Govermental Affairs, 14th Floor, 10030-107th St., Edmonton, Alberta T5J 3E4

Local and Urban Politics

W. Magnusson, Department of Political Science, University of Victoria, Victoria, B.C. V8W 2 Y2

CPSA/CHA Workshop on R. K. Carty/W. P. Ward, Department of Political Science, Canadian Political Communication

Plenaries/Special University of British Columbia, Vancouver, B.C.V6T IWS

\section{Sessions}

